\title{
Microbiological Study On Respiratory Tract Infections In Libya
}

\author{
*A. H. Eldeeb and **E.M. Khashan. \\ *Surgery Depantment, Faculty of Medicine, El-Margeb Univ., and **Clinical Pharmacy \\ Depantment, Faculty of Medical Technology, Mesrata, the Great Socialist People's
}

Libyan Arab Jamahiriya

\begin{abstract}
Introduction: Recent reports revealed that $10 \%$ of the worldwide burden of morbidity and mortality relates to respiratory tract infection.

Patient and methods: Five hundreds and fifty nine clinical strains were isolated and identified from 322 patients suffering from respiratory tract infections. Patients represented different ages, sexes, and types of infections. Out of the 322 patients, 204 were suffering from upper respiratory tract infections and 118 patients were suffering from lower respiratory tract infections. Patients of upper respiratory tract infections were suffering from chronic suppurative otitis media (63 patients), tonsillitis (50 patients), pharyngitis (48 patients), and sinusitis (43 patients).
\end{abstract}

Results: Out of the total isolates, Staphylococcus aureus was the most prevalent organism, followed by Streptococcus pyogenes and Klebsiella pneumoniae (17.71, 12.34, and 11.27\% respectively). Pseudomonas aeruginosa represented 6.26\%. Serratia marcescens and Morganella morganii were the least isolated organisms. The results revealed that $52.42 \%$ of the strains were isolated from males and $47.58 \%$ from females. Staphylococcus aureus was the most prevalent organism in males $(21.16 \%)$ while in females Strept. pyogenes was the most prevalent organism (14.29\%). Also, the study revealed that Staphylococcus aureus was the most frequent isolate in age groups between 1-20, 21-40 and 41-60 years old $(20.85 \%, 17.02 \%$ and $16.67 \%$ respectively). However, both Staphylococcus aureus and Klebsiella pneumoniae were isolated with equal incidences, $12 \%$ each, in elder patients (more than 60 years). The susceptibility pattern of the isolated bacteria to different antimicrobial agents was studied. Both levofloxacin and gatifloxacin showed the highest activity (100\%), followed by ofloxacin and ciprofloxacin (96.44\% and $93.39 \%$, respectively). Those are followed by amikacin $(91.86 \%)$, cefotaxime $(89.31 \%)$, cefoperazone $(86.26 \%)$, gentamicin $(84.22 \%)$, ampicillin-sulbactam (70.48\%), amoxycillin-clavulanic (62.34\%), cefuroxime (62.09\%), lincomycin (61.83\%), vancomycin (61.07\%), chloramphenicol $(57 \%)$, cephalexin $(48.35 \%)$, cephapirin $(45.29 \%)$, erythromycin (44.78\%), and trimethoprim-sulphamethoxazole (43\%). Amoxycillin and tetracycline were the least active ((36.64\% and 32.06\% respectively). Staphylococcus aureus strains resistant to amoxycillin were tested for $B$-lactamase production. Out of the tested strains, $62.5 \%$ were $B$ - lactamase producers and it may be responsible for the resistance to amoxycillin.

In conclusion, the study revealed that evaluation of respiratory tract infections and antimicrobial susceptibility is still in need for more studies. This is due to the continuous development of newly resistant strains and the relatively little number of isolates in some species. Moreover, the differences in the previous antimicrobial treatment, the history of subclinical infections and the immune status of patients involved in each study have increased the difficulty in evaluation.

\section{Itroduction}

Recent reports revealed that $10 \%$ of the worldwide burden of morbidity and mortality relates to respiratory tract infections as they kill an estimated 10 million people annually. The majority of these cases are children under five years old in developing countries (Ball et al., 2002). Upper respiratory tract infections account 


\section{A. H. Eldeeb \& E.M. Khashan.}

for more visits to physicians than any other type of infectious disease. Lower respiratory tract infection is a common cause of hospital admission (Chan et al., 1995 ; Caroll and Reimer, 1996).

Upper respiratory tract infections may move downwards and result in more severe infections of the lower respiratory tract, such as pneumonia or bronchioitis (Sleigh and Timbury, 1998). This progression towards more severe respiratory tract infection is of significant concern in developing countries where pneumonia contributes substantially to childhood death (Wald, 1991).

Different microorganisms are recognized as important etiologic agents of upper respiratory tract infections. S. aureus, Proteus, Klebsiella, and Pseudomonas were reported to be the most important causes of chronic suppurative otitis media (Black, 2002). S. pneumoniae, $H$. influenzae, group A Streptococci and S.aureus are often isolated from cases of sinusitis (Ferranti et al., 1998). S. pyogenes is by far the most clinically important etiologic agent of bacterial pharyngitis (Zwart et al., 2001). Infecting organisms of tonsillitis are identical in type and incidence to those causing pharyngitis with the addition of Staphylococci, S. pneumoniae and Haemophilus species (Brillman and Quenzer, 1992). S. pneumoniae is the most common bacterial pathogen in lower respiratory tract infections (Caroll, 2002).

The problem of increasing antimicrobial resistance of bacterial species commonly isolated from communityacquired respiratory tract infections is of growing concern to microbiologists and infectious disease physicians (Mandell, 1995; Goldstein et al., 1998). The infecting pathogen is often unknown during the acute phase of the infection and therapy is thus empirical. The choice of therapy should reflect the local resistance profile (Felmingham et al., 2000).

The aim of the present work is to study the important microorganisms responsible for respiratory tract infections in Libya to evaluate the anti-bacterial activities of some antimicrobial agents against the isolated strains, and to study the possible mechanisms of resistance of the resistant strains.

\section{Materials And Methods}

\section{Patients, Specimens, and Media:}

Three hundreds and twenty two patients suffering from respiratory tract infections were included in this study and were colleced from outpatient clinics. Out of the 322 patients, 204 patients were suffering from upper respiratory tract infections and 118 patients were suffering from lower respiratory tract infections. Patients of upper respiratory tract infections were complaining from chronic suppurative otitis media (63 patients), tonsillitis (50 patients), sinusitis (43 patients) and pharyngitis (48 patients).

Sterile cotton-tipped swabs were used for collection of upper respiratory tract specimens. Sputum samples were collected in sterile wide-necked and leak proof containers. The collected samples were cultured on blood agar, nutrient agar, MacConkey agar and mannitol salt agar plates. The plates were incubated aerobically at $37^{\circ} \mathrm{C}$ for 24 hours. Sputum samples were spread on slide surfaces for preparation of smears for acid fast stain. The produced colonies were examined morphologically, microscopically and biochemically.

The culture media used were nutrient agar, mannitol salt agar, sulphide indole motility, DNase agar, eosin methylene blue, methyl red-Voges Proskauer (MR-VP) medium and nutrient broth (all are products of Oxoid laboratories). MacConkey agar, triple sugar iron, Christensen's urea agar, Simmons citrate agar and blood agar base (products of Britania laboratories). In addition, brain-heart infusion broth (Biolife) and phenylalanine deaminase agar (Difco) were also used. All media were prepared according to the instructions of the manufacturers. In addition, other media including blood agar, crystal violet blood agar, brain heart infusion with cooked meat particles, cetrimide agar, sugar fermentation medium, nitrate reduction medium and phenolphthalein phosphate agar were prepared in laboratory. 


\section{A. H. Eldeeb \& E.M. Khashan.}

Biochemical activities including catalase, coagulase, DNase, phosphatase production, bacitracin sensitivity, optochin sensitivity, bile solubility, oxidase, urease, nitrate, indole production, $\mathrm{H}_{2} \mathrm{~S}$ production, methyl red, Voges-Proskauer, citrate utilization, amino acid decarboxylation and sugars fermentation tests were performed for identification of each isolate. Biochemical reactions were carried out according to the standard methods of Cruickshank et al., 1975; Koneman et al., 1994 and Collee et al., 1996.

Antimicrobial susceptibility patterns for the isolated strains were studied using Bauer and Kirby method (Bauer et al., 1966). The antimicrobial disks used were amoxycillin $(25 \mu \mathrm{g})$, amoxycillin/clavulanic acid $(20 \mu \mathrm{g} / 10 \mu \mathrm{g}), \quad$ ampicillin/sulbactam $(20 \mu \mathrm{g} / 10 \mu \mathrm{g})$, cephalexin $(30 \mu \mathrm{g})$, cephapirin $(30 \mu \mathrm{g})$, cefuroxime $(30 \mu \mathrm{g})$, cefotaxime $(30 \mu \mathrm{g})$, cefoperazone $(30 \mu \mathrm{g})$, vancomycin $(30 \mu \mathrm{g}), \quad$ gentamicin $(10 \mu \mathrm{g}), \quad$ amikacin $(30 \mu \mathrm{g})$, lincomycin $(2 \mu \mathrm{g})$, erythromycin (15UI), chloramphenicol $(30 \mu \mathrm{g})$, tetracycline (30UI), ciprofloxacin $(5 \mu \mathrm{g})$, ofloxacin $(5 \mu \mathrm{g})$, levofloxacin $(5 \mu \mathrm{g}), \quad$ gatifloxacin $(5 \mu \mathrm{g}), \quad$ trimethoprim/sulpha-methoxazole $(1.25 \mu \mathrm{g}+23.75 \mu \mathrm{g})$. All were products of Oxoid Laboratories. In addition, Bacitracin $(10 \mu \mathrm{g})$ was supplied by Bio-adwic.

\section{Results}

In this study, 559 different clinical strains were isolated from 322 patients suffering from respiratory tract infections (166 male and 156 female) representing different age groups. Out of the 322 patients, 204 were suffering from upper respiratory tract infections and 118 patients were suffering from lower respiratory tract infections. Patients of upper respiratory tract infections were suffering from chronic suppurative otitis media (63 patients), tonsillitis (50 patients), sinusitis (43 patients) and pharyngitis (48 patients). Distribution of the patients according to their age, sex and site of the infection were shown in table (1) and Figure (1).
**Percentage was correlated to the total number of isolates.

The prevalence of microorganisms isolated from the patients in relation to sex was shown in table (3). Data in the table show that $52.42 \%(293 / 559)$ of the strains were isolated from males while $47.58 \%$ (266/559) were isolated from females. $S$. aureus was the most prevalent organism in males $(21.16 \%)$ while in females $S$. pyogenes was the most prevalent organism $(14.29 \%)$.

Table (4) shows the prevalence of microorganisms isolated from the patients according to the type of infection. Of the isolated strains, Staphylococcus aureus was the most frequent in otitis media (24/106, $22.64 \%$ ), tonsillitis $(19 / 88,21.59 \%)$, and Sinusitis (18/82, 21.95\%) followed by Pseudomonas aeruginosa in otitis media (18/106, 16.98\%), Streptococcus pyogenes in tonsillitis (17/88, 19.32\%), and Staphylococcus albus in sinusitis (11/82, $13.41 \%$ ). Data in the table show that 559 different strains were isolated. S. aureus was the most prevalent organism $(17.71 \%)$ followed by $S$. pyogenes $(12.34 \%), K$. pneumoniae (11.27\%), Strept. viridans (10.73\%), Staph. albus (10.38\%), C. albicans (9.3\%), Ps. aeruginosa (6.26\%), S. pneumoniae $(5.37 \%)$, Proteus mirabilis (4.47\%), Diphtheroids spp. (3.22\%), E.coli (2.5\%), Sarcina spp. (1.97\%), Bacillus spp. (1.79\%), Mycobacterium tuberculosis (1.43\%), Proteus vulgaris (0.72\%), Serratia marcescens (0.36\%), and Morganella morganii $(0.18 \%)$.

Table (5) shows the susceptibility patterns of the isolated microorganisms against different antimicrobial agents. Both levofloxacin and gatifloxacin showed the best activity (100\%). Ofloxacin and ciprofloxacin exhibited activities of $96.44 \%$ and $93.39 \%$ respectively. The activities of the other antimicrobials were in the following order: amikacin (91.86\%), cefotaxime $(89.31 \%)$, cefoperazone (86.26\%), 


\section{A. H. Eldeeb \& E.M. Khashan.}

gentamicin (84.22\%), ampicillin-sulbactam (70.48\%), amoxycillin-clavula-nic

$(62.34 \%)$, cefuroxime $(62.09 \%)$, lincomycin $(61.83 \%)$, vancomycin $(61.07 \%)$, chloramphenicol (57\%), cephalexin
(48.35\%), cephapirin (45.29\%), erythromycin $(44.78 \%)$, trimethoprim/sul-phamethoxazole (43\%), amoxycillin (36.64\%) and tetracycline $(32.06 \%)$.

Table (1): Distribution of patients according to their age, sex, and type of infection:

\begin{tabular}{|c|c|c|c|c|c|c|c|c|c|}
\hline \multirow{2}{*}{ Type of Infection } & \multicolumn{9}{|c|}{ Age in years } \\
\cline { 2 - 11 } & \multicolumn{2}{|c|}{$\mathbf{1 - 2 0}$} & \multicolumn{2}{|c|}{$\mathbf{2 1 - 4 0}$} & \multicolumn{2}{|c|}{$\mathbf{4 1 - 6 0}$} & \multicolumn{2}{|c|}{ Above 60 } & \multirow{2}{*}{ Total } \\
\cline { 2 - 11 } & Male & Female & Male & Female & Male & Female & Male & Female & \\
\hline Otitis Media & 21 & 20 & 6 & 7 & 3 & 3 & 3 & 0 & $\mathbf{6 3}$ \\
\hline Tonsillitis & 15 & 10 & 5 & 3 & 6 & 5 & 4 & 2 & $\mathbf{5 0}$ \\
\hline Pharyngitis & 12 & 9 & 6 & 11 & 4 & 3 & 1 & 2 & $\mathbf{4 8}$ \\
\hline Sinusitis & 8 & 14 & 10 & 4 & 2 & 2 & 0 & 3 & $\mathbf{4 3}$ \\
\hline LRT infections & 9 & 10 & 15 & 18 & 19 & 19 & 17 & 11 & $\mathbf{1 1 8}$ \\
\hline Total & $\mathbf{6 5}$ & $\mathbf{6 3}$ & $\mathbf{4 2}$ & $\mathbf{4 3}$ & $\mathbf{3 4}$ & $\mathbf{3 2}$ & $\mathbf{2 5}$ & $\mathbf{1 8}$ & $\mathbf{3 2 2}$ \\
\hline
\end{tabular}

* LRT $=$ lower Respiratory Tract.

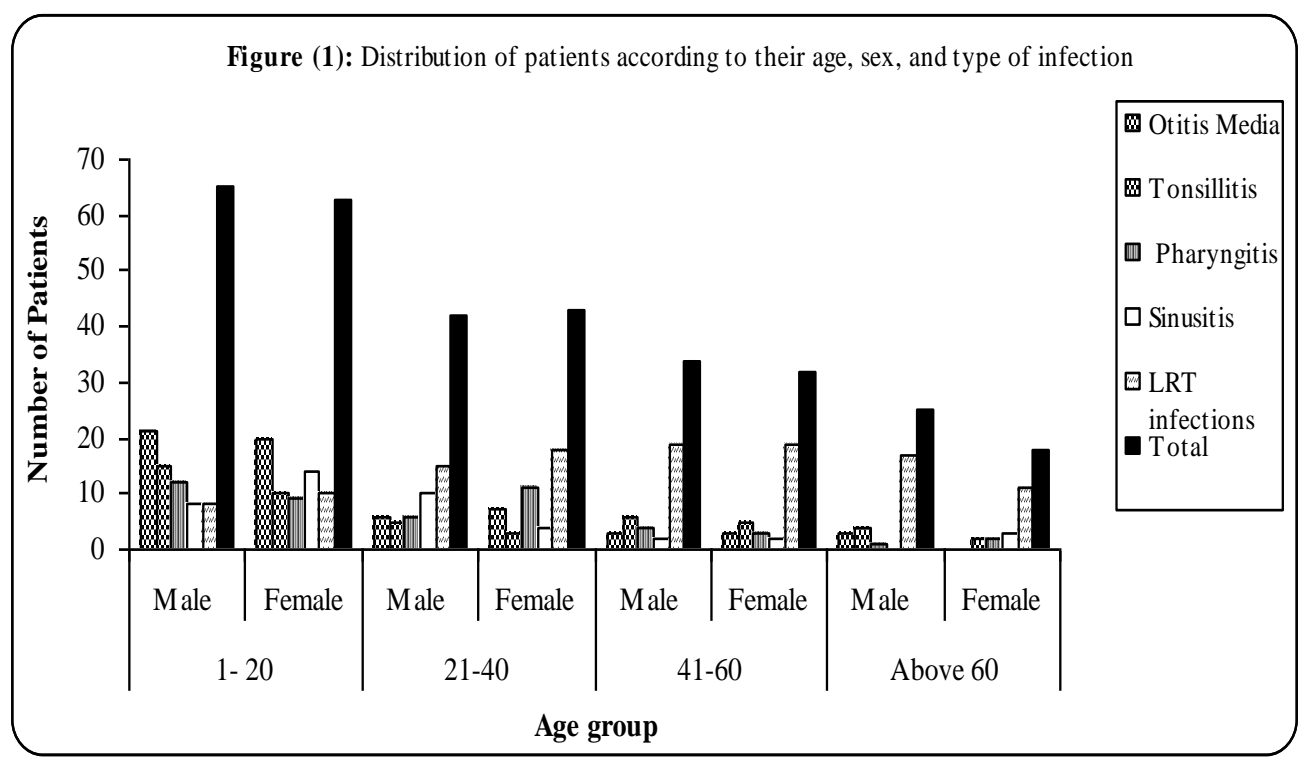

Table (2): Prevalence of microorganisms isolated from the patients in relation to age 
A. H. Eldeeb \& E.M. Khashan.

\begin{tabular}{|c|c|c|c|c|c|c|c|c|c|c|}
\hline \multirow{3}{*}{ Microorganisms } & \multicolumn{10}{|c|}{ Age in years } \\
\hline & \multicolumn{2}{|c|}{$1-20$} & \multicolumn{2}{|c|}{$21-40$} & \multicolumn{2}{|c|}{$41-60$} & \multicolumn{2}{|c|}{$>60$} & \multicolumn{2}{|c|}{ Total } \\
\hline & No & $\%^{*}$ & No & $\% *$ & No & $\% *$ & No & $\% *$ & No & $\% *$ \\
\hline Staphylococcus aureus & 44 & 20.85 & 24 & 17.02 & 22 & 16.67 & 9 & 12 & 99 & 17.71 \\
\hline Staphylococcus albus & 23 & 10.9 & 18 & 12.77 & 10 & 7.58 & 7 & 9.33 & 58 & 10.38 \\
\hline Streptococcus pyogenes & 27 & 12.8 & 21 & 14.89 & 14 & 10.61 & 7 & 9.33 & 69 & 12.34 \\
\hline Streptococcus viridans & 23 & 10.9 & 12 & 8.51 & 19 & 14.39 & 6 & 8 & 60 & 10.73 \\
\hline Streptococcus pneumoniae & 7 & 3.32 & 10 & 7.09 & 6 & 4.55 & 7 & 9.33 & 30 & 5.37 \\
\hline Pseudomonas aeruginosa & 16 & 7.58 & 10 & 7.09 & 7 & 5.3 & 2 & 2.67 & 35 & 6.26 \\
\hline Proteus mirabilis & 11 & 5.21 & 4 & 2.84 & 7 & 5.3 & 3 & 4 & 25 & 4.47 \\
\hline Proteus vulgaris & 4 & 1.9 & 0 & 0 & 0 & 0 & 0 & 0 & 4 & 0.72 \\
\hline Escherichia coli & 7 & 3.32 & 4 & 2.84 & 2 & 1.52 & 1 & 1.33 & 14 & 2.5 \\
\hline Klebsiella pneumoniae & 22 & 10.43 & 14 & 9.93 & 18 & 13.64 & 9 & 12 & 63 & 11.27 \\
\hline Serratia marcescens & 0 & 0 & 2 & 1.42 & 0 & 0 & 0 & 0 & 2 & 0.36 \\
\hline Morganella morganii & 0 & 0 & 0 & 0 & 1 & 0.76 & 0 & 0 & 1 & 0.18 \\
\hline Mycobacterium tuberculosis & 0 & 0 & 1 & 0.71 & 4 & 3.03 & 3 & 4 & 8 & 1.43 \\
\hline Candida albicans & 16 & 7.58 & 14 & 9.93 & 13 & 9.85 & 9 & 12 & 52 & 9.3 \\
\hline Bacillus spp. & 1 & 0.47 & 2 & 1.42 & 2 & 1.52 & 5 & 6.67 & 10 & 1.79 \\
\hline Sarcina spp. & 4 & 1.9 & 0 & 0 & 3 & 2.27 & 4 & 5.33 & 11 & 1.97 \\
\hline Diphtheroids spp. & 6 & 2.84 & 5 & 3.55 & 4 & 3.03 & 3 & 4 & 18 & 3.22 \\
\hline Total & 211 & 100 & 141 & 100 & 132 & 100 & 75 & 100 & 559 & 100 \\
\hline
\end{tabular}

* Percentage was correlated to the number of isolates in each age group.

Table (3): Prevalence of microorganisms isolated from the patients in relation to sex

\begin{tabular}{|l|c|c|c|c|c|c|}
\hline \multirow{2}{*}{ Microorganisms } & \multicolumn{2}{|c|}{ Male } & \multicolumn{2}{c|}{ Female } & \multicolumn{2}{c|}{ Total } \\
\cline { 2 - 7 } & No & \% $^{*}$ & No & \% $^{*}$ & No & \%** $^{*}$ \\
\hline Staphylococcus aureus & 62 & 21.16 & 37 & 13.91 & 99 & 17.71 \\
\hline Staphylococcus albus & 33 & 11.26 & 25 & 9.4 & 58 & 10.38 \\
\hline Streptococcus pyogenes & 31 & 10.58 & 38 & 14.29 & 69 & 12.34 \\
\hline Streptococcus viridans & 28 & 9.56 & 32 & 12.03 & 60 & 10.73 \\
\hline Streptococcus pneumoniae & 11 & 3.75 & 19 & 7.14 & 30 & 5.37 \\
\hline Pseudomonas aeruginosa & 19 & 6.48 & 16 & 6.02 & 35 & 6.26 \\
\hline Proteus mirabilis & 10 & 3.41 & 15 & 5.64 & 25 & 4.47 \\
\hline Proteus vulgaris & 4 & 1.37 & 0 & 0 & 4 & 0.72 \\
\hline Escherichia coli & 6 & 2.05 & 8 & 3.01 & 14 & 2.5 \\
\hline Klebsiella pneumoniae & 33 & 11.26 & 30 & 11.28 & 63 & 11.27 \\
\hline Serratia marcescens & 1 & 0.34 & 1 & 0.38 & 2 & 0.36 \\
\hline Morganella morganii & 1 & 0.34 & 0 & 0 & 1 & 0.18 \\
\hline Mycobacterium tuberculosis & 7 & 2.39 & 1 & 0.38 & 8 & 1.43 \\
\hline Candida albicans & 28 & 9.56 & 24 & 9.02 & 52 & 9.3 \\
\hline Bacillus spp. & 3 & 1.02 & 7 & 2.63 & 10 & 1.79 \\
\hline Sarcina spp. & 5 & 1.71 & 6 & 2.26 & 11 & 1.97 \\
\hline Diphtheroids spp. & 11 & 3.75 & 7 & 2.63 & 18 & 3.22 \\
\hline Total & 293 & 100 & 266 & 100 & 559 & 100 \\
\hline
\end{tabular}

*Percentage was correlated to the number of isolates of each sex. 


\section{A. H. Eldeeb \& E.M. Khashan.}

Table (4): Prevalence of microorganisms isolated from the patients according to the type of infection

\begin{tabular}{|c|c|c|c|c|c|c|c|c|c|c|c|c|}
\hline \multirow{3}{*}{ Microorganisms } & \multicolumn{12}{|c|}{ Type of infection } \\
\hline & \multicolumn{2}{|c|}{ Otitis media } & \multicolumn{2}{|c|}{ Tonsillitis } & \multicolumn{2}{|c|}{ Pharyngitis } & \multicolumn{2}{|c|}{ Sinusitis } & \multicolumn{2}{|c|}{$\begin{array}{c}\text { LRT } \\
\text { infections }\end{array}$} & \multicolumn{2}{|c|}{ Total } \\
\hline & no & $\% *$ & no & $\% *$ & no & $\% *$ & no & $\% *$ & no & $\% *$ & no & $\% * *$ \\
\hline Staphylococcus aureus & 24 & 22.64 & 19 & 21.59 & 15 & 17.24 & 18 & 21.95 & 23 & 11.73 & 99 & 17.71 \\
\hline Staphylococcus albus & 17 & 16.04 & 7 & 7.95 & 5 & 5.75 & 11 & 13.41 & 18 & 9.18 & 58 & 10.38 \\
\hline Streptococcus pyogenes & 7 & 6.6 & 17 & 19.32 & 24 & 27.59 & 8 & 9.74 & 13 & 6.63 & 69 & 12.34 \\
\hline Streptococcus viridans & 3 & 2.83 & 16 & 18.18 & 18 & 20.69 & 5 & 6.1 & 18 & 9.18 & 60 & 10.73 \\
\hline Streptococcus pneumoniae & 0 & 0 & 1 & 1.14 & 2 & 2.3 & 4 & 4.88 & 23 & 11.73 & 30 & 5.37 \\
\hline Pseudomonas aeruginosa & 18 & 16.98 & 0 & 0 & 0 & 0 & 5 & 6.1 & 12 & 6.12 & 35 & 6.26 \\
\hline Proteus mirabilis & 11 & 10.38 & 0 & 0 & 0 & 0 & 7 & 8.54 & 7 & 3.57 & 25 & 4.47 \\
\hline Proteus vulgaris & 2 & 1.89 & 0 & 0 & 0 & 0 & 0 & 0 & 2 & 1.02 & 4 & 0.72 \\
\hline Escherichia coli & 7 & 6.6 & 0 & 0 & 0 & 0 & 5 & 6.1 & 2 & 1.02 & 14 & 2.5 \\
\hline Klebsiella pneumoniae & 8 & 7.55 & 13 & 14.77 & 11 & 12.64 & 9 & 10.98 & 22 & 11.22 & 63 & 11.27 \\
\hline Serratia marcescens & 0 & 0 & 0 & 0 & 0 & 0 & 0 & 0 & 2 & 1.02 & 2 & 0.36 \\
\hline Morganella morganii & 0 & 0 & 0 & 0 & 0 & 0 & 0 & 0 & 1 & 0.51 & 1 & 0.18 \\
\hline $\begin{array}{l}\text { Mycobacterium } \\
\text { tuberculosis }\end{array}$ & 0 & 0 & 0 & 0 & 0 & 0 & 0 & 0 & 8 & 4.08 & 8 & 1.43 \\
\hline Candida albicans & 9 & 8.49 & 7 & 7.95 & 9 & 10.34 & 7 & 8.54 & 20 & 10.2 & 52 & 9.3 \\
\hline Bacillus spp. & 0 & 0 & 0 & 0 & 0 & 0 & 0 & 0 & 10 & 5.1 & 10 & 1.79 \\
\hline Sarcina spp. & 0 & 0 & 3 & 3.41 & 2 & 2.3 & 1 & 1.22 & 5 & 2.55 & 11 & 1.97 \\
\hline Diphtheroids spp. & 0 & 0 & 5 & 5.68 & 1 & 1.15 & 2 & 2.44 & 10 & 5.1 & 18 & 3.22 \\
\hline Total & 106 & 100 & 88 & 100 & 87 & 100 & 82 & 100 & 196 & 100 & 559 & 100 \\
\hline
\end{tabular}

LRT: lower respiratory tract,

- Percentage was correlated to the number of isolates in each type of infection.

- $\quad * *$ Percentage was correlated to the total number of isolates. 
A. H. Eldeeb \& E.M. Khashan. 


\section{A. H. Eldeeb \& E.M. Khashan.}

\section{Discussion}

\section{Prevalence of the isolated strains:}

Respiratory tract infections are the most common causes of childhood morbidity and mortality worldwide, accounting for about $30 \%$ of all childhood deaths in the developing countries (Dixon, 1985 ; Hinman, 1998).

Five hundreds and fifty nine different clinical strains were isolated from 322 patients suffering from different respiratory tract infections. Patients were suffering from chronic suppurative otitis media (63 patients), follicular tonsillitis (50 patients), pharyngitis (48 patients), sinusitis (43 patients) and lower respiratory tract infections (118 patients).

Otitis media is one of common diseases, for which infants and children seek health care. Children who have otitis media in the first year of life are more likely to suffer from chronic infection (Klein et al., 1989; Middleton, 1991). In this study, 106 clinical strains were isolated and identified from 63 patients suffering from chronic suppurative otitis media. Staph. aureus was the most prevalent organism (22.64\%). Ps. aeruginosa was the second $(16.98 \%)$ followed by Staph. albus (16.04\%), Proteus mirabilis (10.38\%), C. albicans (8.49\%), K. pneumoniae (7.55\%), Strept. pyogenes $(6.6 \%)$, E. coli (6.6\%), Strept. viridans $(2.83 \%)$ and Proteus vulgaris $(1.89 \%)$. In a study carried out by Abd-Elrehim et al. (1988), 32 clinical strains were isolated from 25 cases of chronic suppurative otitis media. S. aureus was the most prevalent organism (28\%) followed by Pseudomonas spp. (24\%), Proteus spp. (20\%), E. coli and Bacteroides fragilis (12\% each), Klebsiella, anaerobic Streptococcus, Diphtheroids and Bacteroides melaninogenicus (8\% for each). El-Daly et al. (1990) found that Staph. aureus was the most prevalent organism (39\%) followed by Pseudomonas spp. (29\%), Proteus spp. (21\%), Pneumococci (17\%), Bacteroides and anaerobic Streptococci (12\% each), E. coli and Strept. pyogenes (10\% for each), $H$. influenzae and Klebsiella spp. (9\% each).
Al-Saadawy and El-Tawy (1990) and Del Beccaro et al. (1992) reported higher prevalence for S. aureus (37.5\% and $47.7 \%$ respectively).

Okasha et al. (1995) isolated 28 strains from 24 cases of chronic suppurative otitis media. $S$. aureus was the most frequent organism $(28.6 \%)$ followed by $P$ s. aeruginosa (21.4\%), Proteus mirabilis (14.3\%), Strept. pneumoniae and Aspergillus niger (10.7\% for each), $S$. pyogenes $(7.2 \%), \quad C$. albicans and Aspergillus flavus (3.6\% for each). In a study carried out by Radosz-Komoniewska (1997), S. aureus was the most prevalent organism isolated (45\%) followed by $P$ s. aeruginosa (34\%) and Proteus mirabilis (16\%). Kuczkowski et al. (2000) investigated 150 patients with chronic otitis media. The most frequently observed bacteria were $S$. aureus, Ps. aeruginosa and Proteus mirabilis.

Results of the mentioned studies agree with the present study in having S. aureus the most common organism. The predominance of $S$. aureus and $P$. aeruginosa in chronic suppurative otitis media was also reported by Brook and Burke (1992) and Shaheen et al. (1994). The high prevalence of $S$. aureus could be explained on basis of increased resistance of $S$. aureus to the commonly used antibiotics (Eiff et al., 2001). It could be also attributed to the fact that Staph. aureus is one of the normal flora of the respiratory system and colonizing strains may serve as endogenous reservoirs for overt clinical infections or may spread to other patients (Waldvogel, 1999).

In other studies $P$. aeruginosa was found to be the commonest organism causing chronic suppurative otitis media. Jonsson et al. (1986) reported that $P$. aeruginosa was the most prevalent organism (31.91\%) followed by S. aureus and $S$. albus (29.79\% each), Diphtheroids spp. (25.53\%), Proteus spp. (21.28\%), $\beta$ haemolytic streptococci (10.64\%), Branhamella catarrhalis $(4.26 \%)$ and $H$. influenzae $(2.13 \%)$. The results obtained by Giebink (1989) showed a high importance 


\section{A. H. Eldeeb \& E.M. Khashan.}

of Ps. aeruginosa in the pathogenesis of chronic suppurative otitis media, where it was isolated in $67 \%$ of ear discharge samples and in $31 \%$ of the cases it was the only isolate. Ibrahim et al. (1992) isolated $P$. aeruginosa at a high rate (32\%) followed by Proteus spp. (20\%), H. influenzae and Strept. pneumoniae (8\% each), S. Aureus, $S$. pyogenes and $E$. coli (5\% each).

The study of Altuntas et al. (1996), on chronic suppurative otitis media, revealed that the most common aerobic isolates were Pseudomonas spp., Proteus spp., and S. aureus with recovery rates of $40.7 \%, 21.6 \%$ and $19.1 \%$ respectively. Ghosh et al. (2000) reported that the principal organisms isolated from patients with chronic otitis media were Ps. aeruginosa and Staph. aureus. Zaki (2000) reported a high incidence of $P$. aeruginosa (16.39\%), followed by $S$. aureus (14.75\%), Proteus mirabilis (12.29\%), Staph. albus (10.66\%), E. coli $(9.02 \%)$, Bacillus spp. (7.38\%), Strept. pyogenes and S. viridans $(6.56 \%$ for each) and C. albicans (4.92\%).

The high prevalence of $P$. aeruginosa could be attributed to the fact that $P$. aeruginosa is intrinsically resistant to most commonly used antimicrobial agents. To a considerable extent this resistance is due to outer membrane porins that restrict the entry of antimicrobial agents to the periplasmic space (Talaro and Talaro, 2002 and Abdel-Salam et al., 2003).

The difference in the results may be attributed to that organisms responsible for chronic suppurative media vary from one place to another depending on socioeconomic conditions, which are considered important predisposing etiological factors (Okafor, 1984). Also, the age of patient, the habits of the population as well as the season, during which the study is carried out, may influence the incidence of different organisms (Abd-Elrehim et al., 1988).

Throat infections are common illnesses, for which patients visit primary care physicians (Bisno, 2001). Eighty eight clinical strains were isolated from 50 patients suffering from follicular tonsillitis. Staph. aureus was the most common organism (21.59\%) followed by St. pyogenes (19.32\%), Strept. viridans $(18.18 \%)$, K. pneumoniae $(14.77 \%), S$. albus (7.95\%), C. albicans (7.95\%), Diphtheroids spp. (5.68\%), Sarcina spp. $(3.41 \%)$ and S. pneumoniae (1.14\%).

El-Maraghy (1985) reported that $S$. aureus was the most common orga-nism isolated from chronic tonsillitis cases (48\%) followed by $S$. pyogenes (30\%) and Staph. albus (4\%). Badr (1991) reported that $S$. aureus was the most common organism (76\%) followed by $S$. pyogenes (52\%), $S$. albus (30\%), C. albicans (30\%), Klebsiella spp. (16\%), Strept. pneumoniae and Diphtheroids spp. (14\% for each) Bacillus spp. and Neisseria spp. (8\% for each). Ali (1991) revealed that $S$. aureus was the most prevalent organism in recurrent tonsillitis (56\%) followed by $S$. pyogenes (44\%), Diphtheroids spp. (28\%), Neisseria spp. (20\%), S. albus (16\%) and S. pneumoniae $(12 \%)$.

The previous studies agree with the present one in having $S$. aureus the most prevalent organism in tonsillitis followed by $S$. pyogenes.

Group A streptococcus is by far the most common bacterial cause of acute pharyngitis, accounting for approximately $15 \%$ to $30 \%$ of cases in children and $5 \%$ to $10 \%$ in adults (Uhl et al., 2003). In this study, 87 strains were isolated from 48 patients suffering from pharyngitis. $S$. pyogenes was the most common organism $(27.59 \%)$. S. viridans was the second (20.69\%) followed by S. aureus (17.24\%), $K$. pneumoniae (12.64\%), C. albicans (10.34\%), Staph. albus (5.75\%), $S$. pneumoniae (2.3\%), Sarcina spp. (2.3\%) and Diphtheroids spp.(1.15\%). The high prevalence of $S$. pyogenes $(27.59 \%)$ among patients of pharyngitis was also reported by other studies carried out by Roos et al. (1985); Fluckiger et al. (1998) and Zwart et al. (2001). In these studies, the rate of $S$. pyogenes isolation agrees more or less with that reported by the present study. Epidemiological factors and difference in selection of patients might account for some of these differences.

$S$. viridans was isolated at high rates in both follicular tonsillitis and phary-ngitis (18.18\% and $20.69 \%$ respectively). Strept. 


\section{A. H. Eldeeb \& E.M. Khashan.}

pneumoniae was also isolated but at much lower rates $(1.14 \%$ and $2.3 \%$ respectively). Ibrahim (1978) and Brook et al. (1980) reported that $\alpha$-haemolytic streptococci were the most commonly isolated organism (74\% and $86.96 \%$ respectively). Ali (1991) also reported the isolation of $\alpha$-haemolytic streptococci but at a much lower rate (12\%). Mansy and Al-Saadawy (1990) reported the isolation of $S$. viridans from both severe and moderate cases of acute tonsillitis (3.3\% and $7.1 \%$ respectively). $S$. albus was isolated at an incidence of $7.95 \%$ from follicular tonsillitis cases and 5.75\% from pharyngitis cases. Similar isolation rates were reported by Brook et al. (1980) and Lachin (1989) (8.7\% and 6\% respectively).

Eighty two different strains were isolated from 43 patients suffering from sinusitis. Staph. aureus was the most prevalent organism $(21.95 \%)$. Staph. albus was the second $(13.41 \%)$ followed by $K$. pneumoniae $(10.98 \%), \quad S . \quad$ pyogenes (9.74\%), C. albicans and Proteus mirabilis (8.54\%). S. viridans, $E$. coli and $P$. aeruginosa came next with the same frequency percentage $(6.1 \%)$ followed by Strept. pneumoniae (4.88\%), Diphtheroids spp. (2.44\%) and finally Sarcina spp. (1.22\%). Middleton (1991) found that $40 \%$ of cases of sinusitis were caused by Strept. pneumoniae, $15 \%$ by $H$. influenzae and $15 \%$ by $M$. catarrhalis.

Montgomery et al. (1990) found $S$. aureus and $S$. pneumoniae to be the most common organism isolated from sinusitis cases $(11 \%)$ followed by $\mathrm{H}$. influenzae $(8.3 \%)$, K. pneumoniae $(1.8 \%)$, E. coli (1.2\%) and Proteus spp. (1\%). Zaki (2000) reported a high prevalence of Staph. aureus (26\%) followed by Staph. albus (14\%), K. pneumoniae (12\%), E. coli (11\%), and $S$. viridans $(8 \%)$. The two mentioned studies agree with the present study in having $S$. aureus the most common organism isolated.

Jousimies-Somer et al. (1988) found $H$. influenzae to be the most common organism isolated from sinusitis cases (67\%) followed by S. pneumoniae (27\%), S. pyogenes (8\%), Staph. albus (8\%), $S$. aureus (2\%), Branhamella catarrhalis
(2\%), S. viridans and E. coli (1\% each). The results obtained by Attia (1992) showed that $\mathrm{H}$. influenzae was the most common organism (26\%) followed by Staph. aureus (24\%), Strept. pneumoniae (22\%), Strept. pyogenes (8\%), Strept. viridans, Klebsiella spp. and Ps. aeruginosa (4\% each). The high prevalence of $\mathrm{H}$. influenzae among patients of sinusitis was also reported by Ferranti et al. (1998). Ito et al. (1995) reported that the most common organism in patients suffering from sinusitis was non-haemolytic streptococci (20\%) followed by S. albus (10\%), Micrococcus spp. (10\%) and Pseudomonas spp. (10\%). The present study showed similar isolation rate of $S$. albus (13.41\%).

Lower respiratory tract infections are common and potentially serious infections that afflict children and elderly people throughout the world (McIntosh, 2002). In this study, 196 different strains were isolated from 118 patients suffering from lower respiratory tract infections. Both $S$. aureus and $S$. pneumoniae had the highest frequency $(11.73 \%$ each). K. pneumoniae was the second $(11.22 \%)$ followed by $C$. albicans (10.2\%), S. albus (9.18\%), $S$. viridans $(9.18 \%), S$. pyogenes $(6.63 \%)$, Ps. aeruginosa (6.12\%), Diphtheroids spp. (5.1\%), Bacillus spp. (5.1\%), Mycobacterium tuberculosis (4.08\%), Proteus mirabilis (3.57\%), and Sarcina spp. $(2.55 \%)$. E. coli, Proteus vulgaris and Serratia marcescens came after that with the same incidences $(1.02 \%$ each) and finally Morganella morganii $(0.51 \%)$. The high prevalence of $S$. aureus among patients suffering from lower respiratory tract infections was reported by others (Torres et al.,1989; Rouby et al., 1992; and Kayser, 1992). The study performed by Hawan (2000) illustrated that the highest rate of isolation was for $S$. aureus $(34.33 \%)$ followed by $P$. aeruginosa $(32.84 \%)$ and M. pneumoniae (10.4\%). For Strept. pneumoniae and $C$. albicans the total isolation rate was $9 \%$ each.

Caroll (2002) found that $S$. pneumoniae to be the major cause of community acquired lower respiratory tract infections. Porath et al. (1997) reported a high isolation rate of $S$. pneumoniae 


\section{A. H. Eldeeb \& E.M. Khashan.}

$(42.8 \%)$. The present study showed much lower isolation rate $(11.73 \%)$, which was close to those obtained by Cosentini et al. (1996) (10\%). The high prevalence of $S$. pneumoniae among patients suffering from lower respiratory tract infections was also reported in other studies (Douglas et al., 1995 and Felmingham et al., 2000). K. pneumoniae was isolated at a rate of 11.22\%. Balid (1999) reported a similar isolation rate (14\%). Merchant et al. (1998) and Badawy (2002) reported much higher isolation rates $(34 \%$ and $32.8 \%$ respectively).

The present study showed relatively a high rate of $C$. albicans isolation (10.2\%). Youssef et al. (1980) found C. albicans to be the most commonly isolated fungi from sputum of patients suffering from lower respiratory tract infections. Torres et al. (1989) reported much lower isolation rate $(4.5 \%)$

The present study showed $4.08 \%$ isolation rate of Mycobacterium tuberculosis. This rate is close to that reported by Grange (1993). The difference between isolation rates might be due to the preexisting medical diseases.

\section{Antimicrobial susceptibility patterns:}

Overuse of antibiotics and the emergence of resistant bacteria continue to be the subject of many debates. The isolated bacteria were tested for the antimicrobial susceptibility pattern. For S. Aureus, ofloxacin, levofloxacin, gatifloxacin, amikacin and gentamicin were the most active antibiotics showing $100 \%$ activity followed by ciprofloxacin (98.98\%). Both vancomycin and lincomycin showed equal activities (95.95\% each). El-Daly et al., (1990) reported 84\% activity for gentamicin. Diekema et al. (1999) reported $100 \%$ for vancomycin. Zaki (2000) reported $100 \%$ activity for ofloxacin, ciprofloxacin, amikacin and gentamicin followed by $98.88 \%$ for vancomycin. Hawan (2000) showed that $64.1 \%$ of tested strains were susceptible to ciprofloxacin and $76.92 \%$ to vancomycin. Badawy, (2002) reported $100 \%$ activity for ofloxacin but he reported only $28.6 \%$ for amikacin. Results of the mentioned studies agree with those of the present in having quinolones the most active antibiotics against Staph. aureus. Martin, (2001) recommended the use of ciprofloxacin as an empiric therapy of presumed $S$. aureus infections. Amoxycillin showed a decreased activity $(23.23 \%)$. The production of $\beta$-lactamases was the main mechanism of resistance to amoxycillin as $62.5 \%$ of resistant strains were $\beta$-lactamases producers. New types of plasmid-mediated resistant mutants have been characterized that are capable of producing extended-spectrum $\beta$-lactamases (ESBLs). Strains producing ESBLs are able to inactivate third-generation cephalosporins and monobactams and may only be susceptible to amikacin, quinolones (Murthy, 2001).

Levofloxacin and gatifloxacin showed the greatest activities (100\%) against $S$. pneumoniae followed by ofloxacin and ciprofloxacin (90\% each), cefotaxime and cefoperazone $(86.67 \%$ each), lincomycin and vancomycin $(83.33 \%$ each), cefuroxime (70\%) and amikacin (63.33\%). Ampicillin/sulbactam and amoxicillin /clavulanic came next $(53.33 \%$ each $)$ followed by amoxycillin, and gentamicin (50\% each). Cephalexin, cephapirin and erythromycin showed equal activities (46.67\% each) followed by chloramphenicol (43.33\%), trimethoprim/ sulphamethoxazole $(33.33 \%)$ and tetracycline $(30 \%)$.

The results obtained by Diekema et al. (1999) showed $85.8 \%$ activity for vancomycin. This result is close to that obtained in the present study. Hawan (2000) reported $94.74 \%$ activity for ciprofloxacin and $84.2 \%$ for vancomycin. These results agree with that obtained by the present work. The present study also agree with that of Felmingham et al. (2000) where it showed significant resistance to erythromycin and $\beta$-lactam antibiotics while the resistance to quinolones was uncommon.

The present study showed $50 \%$ activity for amoxycillin and $46.67 \%$ for erythromycin. All strains that were amoxycillin resistant were also erythromycin resistant. The prevalence of penicillin resistance in Pneumococci has risen steeply over the past years in some countries. 


\section{A. H. Eldeeb \& E.M. Khashan.}

Macrolide resistance among Pneumococci has increased dramatically in most countries. Because of the local spread of multi resistant clones, a relationship has been suggested between the prevalence of resistance to macrolides and penicillin (Dagan et al., 2001).

Levofloxacin, gatifloxacin, and vancomycin had the greatest activity $(100 \%)$ against $S$. pyogenes followed by ofloxacin $(98.55 \%)$, lincomycin $(97.1 \%)$, cefotaxime $(95.65 \%)$, ciprofloxacin and cefoperazone $(91.3 \%$ each), cefuroxime (85.5\%), amikacin (84.06\%), ampicillin/ sulbactam and gentamicin (82.61\% each), amoxycillinclavulanic(79.71\%), cephalexin (78.26\%), amoxycillin (75.36\%), erythromycin (73.91\%), cephapirin (69.57\%), chloramphenicol (65.21\%), trimethoprim/ sulphamethoxazole (62.32\%), and tetracycline $(50.72 \%)$.

El-Daly et al. (1990) investigated the antimicrobial activity of different antimicrobial agents against isolates of $S$. pyogenes. The study reported $25 \%, 50 \%$, $25 \%$ and $25 \%$ for erythromycin, amoxycillin, chloramphenicol and tetracycline respectively. The present study showed higher activities for the same antibiotics. Baquero et al. (1999) reported that the susceptibility of Strept. pyogenes was $73 \%$ for erythromycin and $90 \%$ for ciprofloxacin. The high activity of ofloxacin $(100 \%)$ was demonstrated by Badawy (2002).

Levofloxacin and gatifloxacin showed the best activity against S. albus $(100 \%)$ followed by amikacin (98.28\%), lincomycin (96.55\%) and ofloxacin (94.83\%). Ciprofloxacin showed high activity against the tested strains $(91.38 \%)$ followed by vancomycin $(87.93 \%)$ and ampicilln/sulbactam (86.21\%), cefotaxime $(84.48 \%)$,amoxycillinclavulanic $(81.03 \%)$, cefoperazone $(80.03 \%)$, erythromycin $(72.41 \%)$, cefuroxime $(70.69 \%)$, chloramphenicol $(68.97 \%)$, trimethoprim/sulphamethoxazole (67.24\%). Cephalexin and cephapirin came next $(55.17 \%$ and $51.72 \%$ respectively) followed by amoxycillin $(48.28 \%)$ and tetracycline (43.1\%). Zaki (2000) reported $100 \%$ activity for ofloxacin, $96.36 \%$ for gentamicin, $94.55 \%$ for amikacin, 92.73\% for ciprofloxacin, and $85.45 \%$ for vanco-mycin. Murray et al. (2002) declared that $S$. albus was sensitive to quinolones, vancomycin and trimethoprim/-sulphamethoxazole.

Ps. aeruginosa showed the following susceptibility pattern: levofloxacin, gatifloxacin, ofloxacin and ciprofloxacin showed the greatest activity (100\%) followed by amikacin $(97.14 \%)$, gentamicin $(94.28 \%)$, cefoperazone $(85.71 \%)$, cefotaxime (82.86\%), amoxycillin/ clavulanic (37.14\%), amoxycillin (28.57\%), tetracycline $(17.14 \%)$ and chloramphenicol (11.43\%). Wilkie et al. (1992) reported that new quinolones such as norfloxacin and ciprofloxacin had a broad spectrum of activity and were effective against grampositive and gram-negative bacteria including Pseudomonas spp.. Gebreel et al. (2000) reported in their study on Ps. aeruginosa isolates that sensitivity to ciprofloxacin, ofloxacin and ampicillin was $100 \%, 100 \%$, and $0 \%$, respectively. These results are in agreement with those obtained in the present study. Only $28.57 \%$ of $P$. aeruginosa isolates were susceptible to amoxicillin. The low susceptibility of Ps. aeruginosa to $\beta$-lactam antibiotics like amoxycillin was also reported by AbdelSalam et al. (2003).

Proteus mirabilis showed the following susceptibility pattern: levofloxacin, gatifloxacin and cefotaxime showed $100 \%$ activity. Ofloxacin showed an activity of $96 \%$ followed by ciprofloxacin and amikacin (92\% each), cefoperazone (88\%), gentamicin (84\%), ampicillin/ sulbactam (64\%), amoxycillin-clavulanic (52\%), chloramphenicol (48\%), amoxycillin (44\%), trimethoprim/ sulphamethoxazole (40\%), cefuroxime (32\%), tetracycline (16\%), cephalexin (8\%), cephapirin (4\%).

These results were consistent with the results of other studies that showed the high activity of aminoglycosides and quinolones against Proteus mirabilis (Abou-Sayed, 1988; Zaki, 2000).

Levofloxacin and gatifloxacin showed $100 \%$ activity against $\mathrm{K}$. pneumoniae isolates. Ofloxacin, ciprofloxacin and amikacin also showed high activities $(92.06 \%, 90.48 \%$ and $90.48 \%$ respectively). 


\section{A. H. Eldeeb \& E.M. Khashan.}

The activities of the other of antimicrobials were in the following order: cefoperazone $(88.89 \%)$, cefotaxime $(87.3 \%)$, gentamicin (82.54\%), chloramphenicol (73.02\%), ampicillin-sulbactam $(50.79 \%)$, cefuroxime (47.62\%), tetracycline (39.68\%), cephalexin $(33.33 \%)$, cephapirin $(28.57 \%)$, trimethoprim/sulphamethoxazole $(22.22 \%)$, amoxycillin-clavulanic (20.63\%), and amoxycillin $(4.76 \%)$.

Baron et al. (1994) found that $K$. pneumoniae was susceptible to aminoglycosides, quinolones and third generation cephalosporins. The present study showed good activities for aminoglycosides, quinolones and for third generation cephalosporins. El-Daly et al. (1990) reported $100 \%$ activity for gentamicin. Kamal (1999) found that amikacin and ciprofloxacin were the most potent antimicrobials against Klebsiella spp.

For E. coli, levofloxacin, gatifloxacin and amikacin showed the best activity $(100 \%)$. Ofloxacin and ciprofloxacin showed $92.86 \%$ and $85.71 \%$ respectively followed by gentamicin $(78.57 \%)$, cefotaxime $(71.43 \%)$, cefoperazone $(64.29 \%)$ and ampicillin-sulbactam (50\%), amoxycillinclavulanic $(35.72 \%)$, chloramphenicol (28.57\%), and cefuroxime (21.43\%). Amoxycillin, Cephalexin and trimethoprim/ sulphamethoxazole came next (14.29\% each) followed by both tetracycline and cephapirin $(7.14 \%$ each). Baron et al. (1994) recommended the use of aminoglycosides and quinolones for treatment of $\mathrm{E}$. coli infections. The present study declared that the highest activity was obtained by aminoglycosides and quinolones. Oteo et al. (2002) investigated the susceptibility of E. coli. The study reported $82.81 \%$ activity for ciprofloxacin and $93.61 \%$ for gentamicin. The present study showed similar activity for ciprofloxacin.

The present study showed decreased activity of amoxycillin (14.29\%) against E. coli isolates. High antibiotic consumption selects for resistance in microorganisms of commensal flora. Most E. coli infections involve organisms originating from the patient's own gut flora, and the resistance of these is very likely to reflect previous patterns of prescribing in a community. This could be the cause of more prevalent resistance to amoxycillin in children, who probably consume more of this class of antibiotics than adults (Osterblad et al., 2000).

\section{References}

1. Abd-Elrehim $\mathbf{S}$ I, Attia $\mathbf{M} \mathbf{W}$ Nafie E, Assal A U and Arafa R M I (1988): Bacteriological study of acute and chronic otitis media. Az. J. Microbiol., 3: 102-112.

2. Abdel-Salam $H$ A, Atia $A$ and Aboulwafa M M (2003): Characteri-zation of Pseudomonas aeruginosa and its multidrug resistant mutants implicated in chronic suppurative otitis media. N. Egypt. J. Microbiol., 4: 9-21.

3. Abou-Sayed M E (1988): Epidemiological studies on some Gram negative non-lactose fermenting bacteria of the family Enterobacteriaceae. A thesis of M. D. in Microbiology, Faculty of Pharmacy, Al-Azhar University.

4. Ali M A M (1991): Microbiology of recurrent tonsillitis in adults and children. A thesis of M. D., E.N.T. Department, Faculty of Medicine, Al-Azhar University.

5. Al-Saadawy M M M and El-Tawy M A (1990): Microbial flora of the nasoph-arynx and secretory otitis media in young children. Az. J. Microbiol., 10: 65-77.

6. Al-Saadawy M M M, Seyam $\mathbf{E} \mathbf{A}$ and Mohamed M F M (1991): Studies on beta-lactamase producing bacteria in chronic tonsillitis. Az. J. Microbiol., 14: 91-100.

7. Altuntas, A., Aslan, A., Eren, N.., Unal, A. and Nalca, Y. (1996): Susceptibility of microorganisms isolated from chronic suppurative otitis media to ciprofloxacin. Eur. Arch. Otorhinolaryngol., 253: 364366.

8. Attia M F (1992): Microbiology of acute sinusitis. A thesis of M. D., E.N.T. department, Faculty of Medicine, AlAzhar University.

9. Badawy $A$ Z (2002): Causative organisms of nosocomial pneumonia and their antibiotic sensitivity patterns. A thesis of M. D. in Microbiology, Faculty of Medicine, Cairo University.

10. Badr M A (1991): Microbiological and serological studies of throat infection among Egyptians. A thesis of M. D. in Microbiology, Faculty of Pharmacy, AlAzhar University. 


\section{A. H. Eldeeb \& E.M. Khashan.}

11. Ball P, Baquero $\mathbf{F}$, Cars $\mathbf{O}$, File $\mathbf{T}$, Garau J, Klugman K, Low D E, Rubinstein E, Wise $R$ and the consensus group on resistance and prescribing in respiratory tract infection (2002): Antibiotic therapy of community respir-atory tract infections: strategies for optimal outcomes and minimized resistance eme-rgence.J.Antimicrob.

Chemother.,49:31-40.

12. Baron $E \mathbf{J}$, Peterson $L R$ and Finegold $S$ M (1994): Methods for identification of etiological agent of infectious disease. In: Bailey and Scott's diagnostic microbiology, $9^{\text {th }}$ edn., Mosby-Year Book Inc., USP. pp. 322-332.

13. Baquero F, Rodriguez J A, Lomas J $D$ and the Spanish surveillance group for respiratory pathogens (1999): Antimicrobial resistance of 914 beta-haemolytic streptococci isolated from pharyngeal swabs in Spain. Antimicrob. Agents. Chemother., 43: 178-180.

14. Balid M I (1999): Uncommon bacterial lower respiratory tract infections. A thesis of M. D. in Microbiology, Faculty of Medicine, Cairo University.

15. Bauer A W, Kirby W M M, Sherris J C and Turck M (1966): Antibiotic susceptibility testing by a standardized single disk method. Am. J. Clin. Path., 45: 493-499.

16. Bisno A L (2001): Acute pharyngitis. N. Engl. J. Med., 344: 205-211.

17. Brillman J C and Quenzer R W (1992): The respiratory system. In: Infectious Disease in Emergency Medicine, $1^{\text {st }}$ edn., Ch. 21, Little, Brown and Company, Boston. pp. 497-517.

18. Black J G (2002): Diseases of the respiratory system. In: Microbiology Principles and explorations, $5^{\text {th }}$ edn. Ch. 21, pp. 577-607.

19. Brook I and Burke $P$ (1992): The management of acute, serous and chronic otitis media: The role of anaerobic bacteria. J. Hospit. Inf., 22: 75-87.

20. Brook I, Yocum $P$ and Shah K (1980): Surface versus core tonsillar aerobic and anaerobic flora in recurrent tonsillitis. JAMA, 244: 1696-1698.

21. Caroll $K$ and Reimer $L$ (1996): Microbiology and laboratory diagnosis of upper respiratory tract infections. Clin. Infect. Dis.; 23: 442-448.

22. Caroll K C (2002): Laboratory diagnosis of lower respiratory tract infections. J. Clinc. Microbiol., 40: 3115-3120.

23. Chan R, Hemeryck L, Regan M, Clancy L and Feely J (1995): Oral versus intravenous antibiotics for community acquired lower respiratory tract infection in general hospital: open randomized controlled trial. BMJ, 310: 1360-1366.

24. Collee J G, Fraser AG, Marmion B P and Simmons A (1996): Tests for identification of bacteria. In: Mackie \& McCartney practical medial microbiology, $14^{\text {th }}$ edn., Churchill Livingstone In., New York. pp. 131-149.

25. Cosentini R, Blasi $\mathbf{F}$ and Raccanelli R. (1996): Severe community acquired pneumonia. Respiration., 63: 61-65.

26. Cruickshank R, Duguid J P, Marmion, B P and Swain R H (1975): Medical microbiology, vol. 2, $12^{\text {th }}$ edn., Churchill Livingstone Inc., Edinburgh, London and New York.

27. Dagan R, Klugman K P, Craig W A. and Baquero F (2001): Evidence to support the rationale that bacterial eradication in respiratory tract infection is an important aim of antimicrobial therapy. J. Antimicrob. Chemother., 47: 129-140.

28. Diekema D J, Coffman S L, Marshall S A, Bwach M L, Rolston KV and Jones, RN (1999): Comparison of activities of broad spectrum $\beta$-lactam compounds against 1,128 gram-positive cocci recently isolated in cancer treatment centers. Antimicrob. Agents. Chemother., 43: 940943.

29. Del Beccaro, $M$ A, Mendelman $\mathbf{P} M$, Inglis A F, Richardson M A, Duncan N O, Clausen CR and Stull T L (1992): Bacteriology of acute otitis media. J. Pediatr., 120: 81-84.

30. Dixon $R$ E (1985): Economic costs of respiratory infections in the United States. Am. J. Med., 78: 45-51.

31. Douglas G, Niederman M S, Broughton, W A, Graven D E and other members of the American Thoracic Society (1995): Hospital acquired pneumonia in adults: Diagnosis, assessment of severity, initials antimic-robial therapy and preventive strategies. Am. J. Med., 153: 1711.

32. Eiff C V, Becker K, Machka K, Stammer $H$ and Peters G (2001): Nasal carriage as a source of Staphylococcus aureus bacteremia. N. Engl. J. Med., 340: 556-561.

33. El-Daly O M, Shaheen A A M, Wegd-an, A A, Abdel-Azim M, Rashad A $M$ and El-Shewy M E (1990): Recurrent suppurative otitis media is it a new infection or relapse? Az. J. Microbiol., 7: 261-270. 


\section{A. H. Eldeeb \& E.M. Khashan.}

34. El-Maraghy M Y (1985): Serological and bacteriological tests in chronic tonsillitis, A Ph. D. thesis, E.N.T. Department, Faculty of Medicine, Al-Azhar University.

35. Ferranti $S$ D, Ioannidis J P, Lau J, Anninger W V and Barza M (1998): Are amoxycillin and folate inhibitors are effective as other antibiotics for acute sinusitis ? A meta-analysis. BMJ, 317: 632-637.

36. Felmingham $D$, Grünebergand $R \mathbf{N}$ and the Alexander project group (2000): The Alexander Project 1996-1997: Latest susceptibility data from this international study of bacterial pathogens from community acquired lower respir-atory tract infections. J. Antimicrob. Chemother., 45: 191-203.

37. Fluckiger U, Jones K F and Fischetti V A (1998): Immunoglobulins to group A Streptococcal surface molecules de-rease adherence to and invasion of human pharyngeal cells. Infect. Immunol., 66: 974979.

38. Gebreel H M, Abu-Shady M R, Moustafa E A and Mohamed W F (2000): Incidence of surgical wound infection after cardiac and thoracic surgery. Az. J. Microbiol., 48: 7-18.

39. Ghosh S, Panarese A, Parker A J and Bull P D (2000): Quinolone ear drops for chronic otitis media. BMJ., 321: 126-127.

40. Giebink, G.S. (1989): The microbiology of otitis media. Pediatr. Infect. Dis.J.,8: 18-20.

41. Gold H S and Moellering R C (1996): Antimicrobial drug resistance. N. Engl. J. Med., 335: 1445-1453.

42. Goldstein, F.; Bryskier, A.B.; Appelb-aum, P.C.; Bauernfeind, A.; Jacobs, M. and Schito, G.C. (1998): The etiology of respiratory tract infections and the antibacterial activity of fluoroquinolones and other oral antibacterial agents against respiratory pathogens. Clin. Microbiol. and Infect., 4: 28-38

43. Grange, J.M. (1993): Mycobacterium. In: Medical microbiology, Greenwood, D.; Slack, R.C. and Prutherer, J.F. (eds.), $14^{\text {th }}$ edn., Ch. 19, Churchill Livingstone, USA. pp. 241-252.

44. Hawan, S.M. (2000): Lower respiratory tract infection among critically ill pati-ents in Alexandria. A thesis of M. D. in Microbiology, High Institute of Public Health, Alexandria University.

45. Hinman, A.R. (1998): Global progress in infectious diseases control. Vaccine, 16: 1116-1121.

46. Ibrahim, A.K.K. (1978): Staphylococcal throat infections. A thesis for M.D., Microbiology department, Faculty of Medicine, Ain Shams University.

47. Ibrahim, O.A.H.; Farweez, A.T.; Aboul-Khair, M. and Rashed, R. (1992): Microbiological correlation of the middle ear and nasopharynx in chronic supp-urative otitis media. Az. J. Microbiol., 15: 1-13.

48. Ito, J.; Mizuta, K.; Ogawa, H.; Suzuki, T.; miyata, H.; Kato, N. and Ueno, K. (1995): Bacteriology of chronic otitis media, chronic sinusitis. Clinc. Infect. Dis., 20: 214-219.

49. Jonsson L, Schwan A, Thomander LG and Fabian, P. (1986): Aerobic and anaerobic bacteria in chronic suppurative otitis media: a quantitative study. Acta Otolaryngol., 102: 410414.

50. Jousimies-Somer, H.; Savolainen, S. and Ylikoski, J.S. (1988): Bacteriological findings of acute maxillary sinusitis. J. Clin. Microbiol., 26: 1919-1925.

51. Kamal, W. (1999): Microbial infections in burned and postoperative patients in some Egyptian hospitals. M. Sc. Thesis, Faculty of Pharmacy, Azhar University, Assiut, Egypt.

52. Kayser, F.H. (1992): Changes in the spectrum of organisms causing respiratory tract infections. Postgrad. Med. J., 68: 1723.

53. Klein, J.O.; Tos, M.; Hussl, B.; Naunton, R.F.; Ohyama, M. and Van Cauwenberge, P.B. (1989): Definition and classification. Ann. Otol. Rhinol. Laryngol., 98: 10

54. Koneman, E.W.; Allen, S.D.; Janda, W.M.; Schreckenberger, P.C. and Winn, W.C. (1994): Introduction to diagnostic microbiology, J. B. Lippincott Company, USA.

55. Kuczkowski, J.; Samet, A. and Brzoznowski, W. (2000): Bacteriologic evaluation of otitis externa and chronic otitis media. Otolaryngology, 54: 551-556.

56. Lachin, M.F.E. (1989): Aerobic and anaerobic bacteria in tonsils of children with recurrent tonsillitis. A thesis for M.D., E.N.T. department, Faculty of Medicine, Al-Azhar University.

57. Liang, W.; Huang, H.; Lin, R. and Hou, W. (2003): Screening for natural inhibitors of penicillinase by copolymerization of hydrolyzed starch or glycogen in sodium dodecylsulfate polyacrylamide gels for detecting 


\section{A. H. Eldeeb \& E.M. Khashan.}

penicillinase activity. Bot. Bull. Acad. Sin., 44: 187-191.

58. Mandell, L.A. (1995): Community acquired pneumonia: Etiology, epidemio-logy and treatment. Chest, 108: 35-42.

59. Mansy, E.S.M and Al-Saadawy, M.M.M. (1990): Microbiology of acute tonsillitis. Az. J. Microbiol., 7: 102-113.

60. Martin, (2001): Ciprofloxacin for empiric therapy of presumed Staphylococcus aureus infection. BMJ., 322: 906- 913.

61. McIntosh, K. (2002): CommunityAcquired Pneumonia in Children. N. Engl. J. Med., 346: 429-437.

62. Merchant, M.; Karnad, D.R.; Kanbur, A.A. (1998): Incidence of nosocomial pneumonia in a medical intense care unit and general medical ward patients in public hospital in Rombay. India. J. Hosp. Infect., 39: 143-148.

63. Middleton, D.B. (1991): An approach to pediatric upper respiratory infections. American Family Physician, 44: 33-41.

64. Montgomery, J.M.; Lehmann, D.; Smith, T.; Michael, A.; Joseph, B.; Lupiwa, T.; Coakley, C.; Spooner, V.; Best, B.; Riley, I.D. and Alpers, M.P. (1990): Bacterial colonization of upper respiratory tract and its association with lower respiratory tract infections in highland children of Papua New Guinea. Rev. Infect. Dis., 12: 10061016.

65. Murray P R, Rosenthal K S, Kobayashi, G S, Pfaller M A (2002): Medical microbiology, $4^{\text {th }}$ edn., Mosby Inc., A Harcourt Health Sciences Company, Philadelphia.

66. Murthy, R, (2001): Implementation of strategies to control antimicrobial resistance. Chest, 119: 405-411.

67. Okafor, B.C. (1984): The chronic discharging ear in Nigeria. J. Laryngol. Otol., 98: 113-119.

68. Okasha, M.M.K.; Serry, F.M. and ElShazly, E. (1995): suppurative otitis media in rural area. Az. J. Microbiol., 30: 31-44.

69. Osterblad, M.; Hakanen, A.; Manninen, R.; Leistevuo, T.; Peltonen, R. and Meurman, O. (2000): A between-species comparison of antimicrobial resistance in enterobacteria in fecal flora. Antimicrob. Agents. Chemother, 44: 1479-84.

70. Porath A, Schlaeffer, F. and Lieberman, D. (1997): The epidemiology of community acquired pneumonia among hospitalized adults. J. Inf., 34: 41-48.

71. Oteo, J.; Campos, J. and Baquero, F. (2002): Antibiotic resistance in 1962 invasive isolates of Escherichia coli in 27 Spanish hospitals participating in the European Antimicrobial Resistance Surveillance System. J. Antimicrob. Chemother, 50: 945-952.

72. Radosz-Komoniewska, H.; Pelczar, B.; Nowakowska, M.; Zientara, M. and Rudy, M. (1997): Bacterial flora in chronic inner ear infections in adults. Med. Dosw. Mikrobiol., 49: 8387.

73. Roos K, Holm, S.E. and Ekedahl, C. (1985): Treatment failure in acute streptococcal tonsillitis in children over the age of 10 and in adults: Clinical and therapeutic aspects. Scand. J. Infect. Dis., 17: 357-364.

74. Rouby J, Lassale E M, Poete P, Nicolas M, Bodin L, Jarlier V, Charpentier Y L, Grosset $J$ and Viars P (1992): Nosocomial bronchopneumonia in critically ill patients. Ann. Rev. Respir. Dis., 146: 1059-1066.

75. Shaheen, A.A.; Samour, S.H.; Rashad, A and El-Said, E.E. (1994): Bacteriological study of otitis media in adults. Egy. J. Med. Microbiol., 3: 303308.

76. Sleigh, J.D. and Timbury, M.C. (1998): Respiratory tract infections. In: Notes on Medical Bacteriology, $5^{\text {th }}$ edn. Ch. 27, Churchill Livingstone and Robert Stevenson, UK. pp. 173-198.

77. Sykes, R.B. (1978): Methods for detecting $\beta$-lactamases. In: Reeves, D.S.; Phillips, I.; Williams, J.D. and Wise, R. (eds.). Laboratory methods in Antimicrobial Chemotherapy, Churchill Livingstone, Ch. 7. pp. 64-69. 


\section{A. H. Eldeeb \& E.M. Khashan.}

78. Talaro, K.P. and Talaro, A. (2002): The gram-negative bacilli of medical importance. In: Microbiology, $4^{\text {th }}$ edn., Ch. 20, McGram-Hill Companies, Inc., Boston. pp. 604.

79. Torres, A.; Bellacasa, J.P. and Xaubet, A. (1989): Diagnostic value of quantitative cultures of bronchoalveolar lavage and telescoping plugged catheters in mechanically ventilated patients with bacterial pneumonia. Ann. Rev. Respir. Dis., 140: 306-310.

80. Tunér, K. and Nord, C.E. (1983): Betalactamase producing microorganisms in recurrent tonsillitis. Scand. J. Infect, Dis., 39: 83-85.

81. Uhl, J.R.; Adamson, S.C.; Vetter, E.A.; Schleck, C.D.; Harmsen, W.S.; Iverson, L.K.; Santrach, P.J.; Henry, N.K. and Cockerill, F.R. (2003): Comparison of LightCycler PCR, Rapid Antigen Immunoassay, and Culture for Detection of Group A Streptococci from Throat Swabs. J. Clin. Microbiol., 41: 242-249.

82. Wald, E.R.; Milmoe, G.J.; Bowen, A.; Ledesma-Medina, J.; Salamon,
N. and Bluestone, C.D. (1991): Acute maxillary sinusitis in children. N. Engl. J. Med., 304: 749-754.

83. Waldvogel, F.A. (1999): New resistance in Staphylococcus aureus. N. Engl. J. Med., 340: 556-557.

84. Wilkie M E, Almond M K and Marsh F $P$ (1992): Diagnosis and management of urinary tract infection in adults. BMJ, 305 : $1137-41$

85. Youssef $\mathbf{H} \mathbf{H}$, Refaei $M \mathbf{K}$ and Youssef Y A (1980): Fungi and the lung. J. Chest Dis. and Tuberc., 23: 119.

86. Zaki S A (2000): Microbiological studies on certain microorganisms causing respiratory tract infection. A thesis of M. D. in Microbiology, Faculty of Pharmacy (Girls), Al-Azhar University.

87. Zwart, S, Ruijs G J, Sachs A P Schellekens J F and De Melke R A (2001): Potentially virulent strains and high colony counts of group A $\beta$ haemolytic streptococci in pharyngitis patients having a delayed recovery or a complication. J. Antimicrob. Chemother, 49: 689-691. 
A. H. Eldeeb \& E.M. Khashan.

\title{
دراسة ميكروبيولوجية لعدوى الجهاز التنفسى فى الجماهيرية الليبية
}

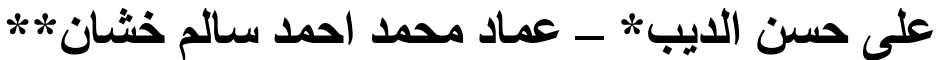

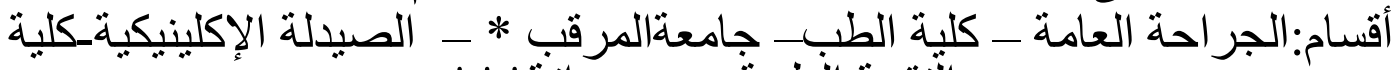

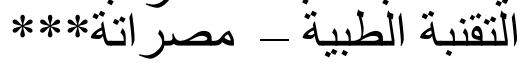

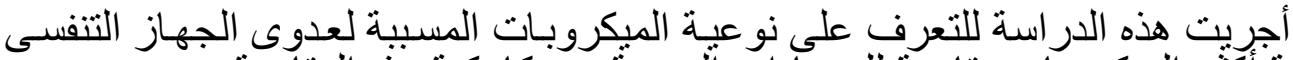

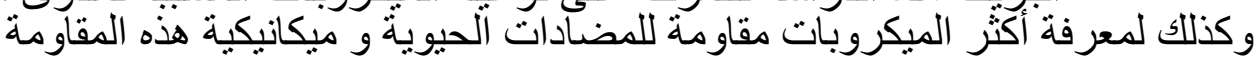

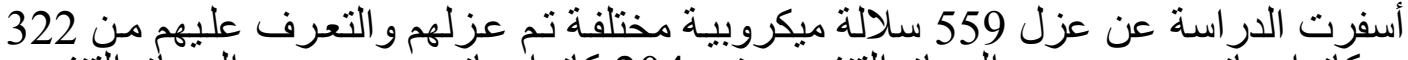

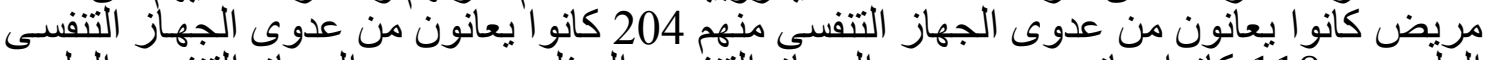

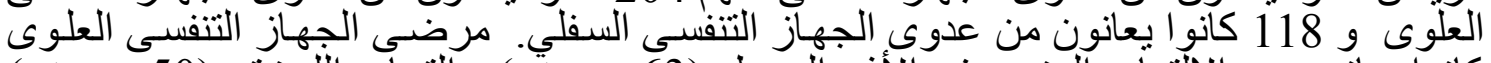

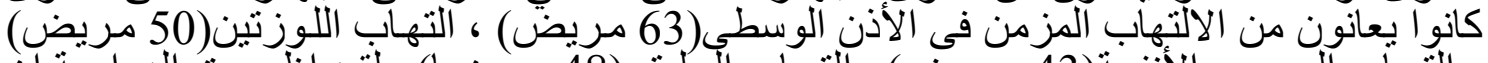

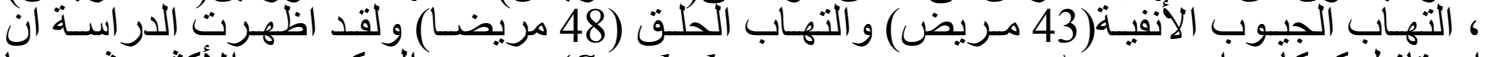

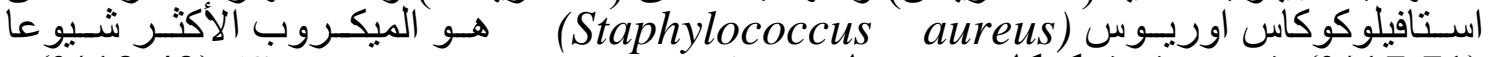

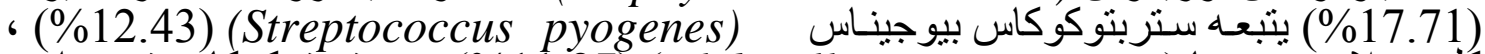

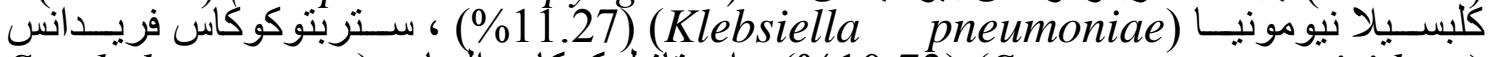
Staphylococcus ) (10.73) (Streptococcus viridans)

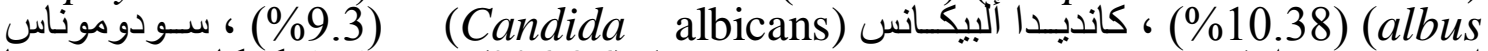

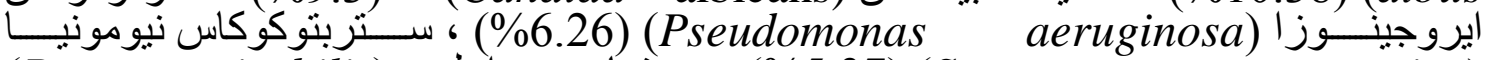

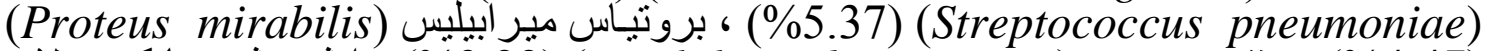

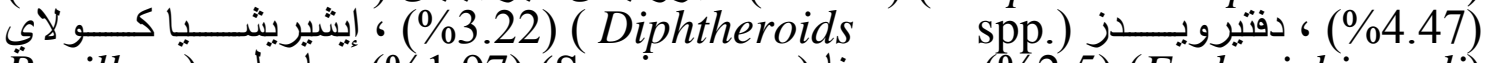

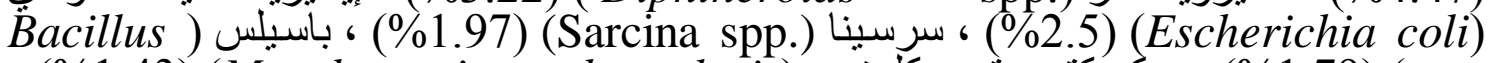

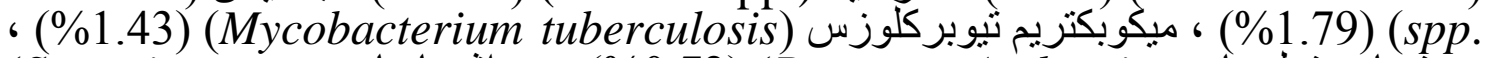

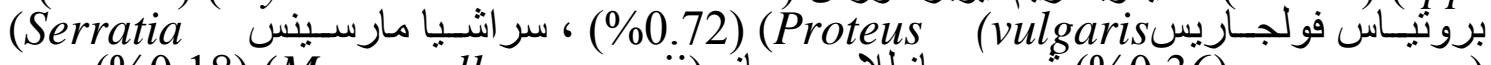

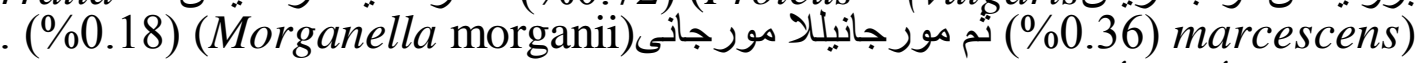

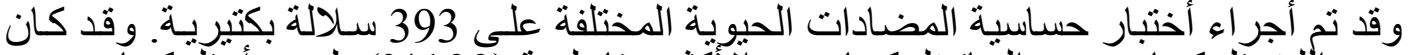

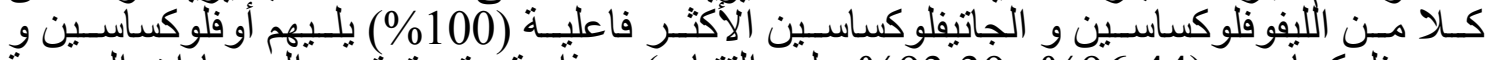

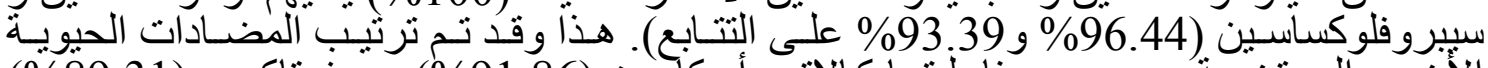

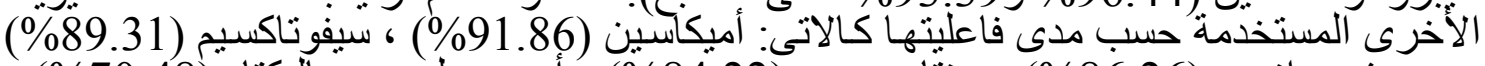

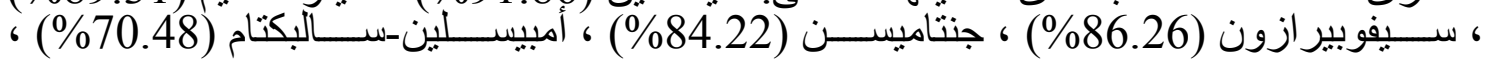


A. H. Eldeeb \& E.M. Khashan.

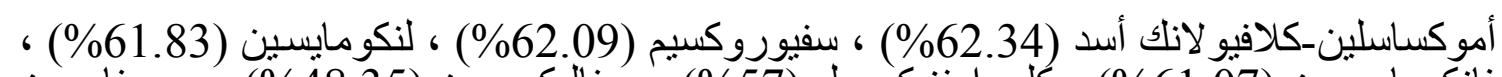

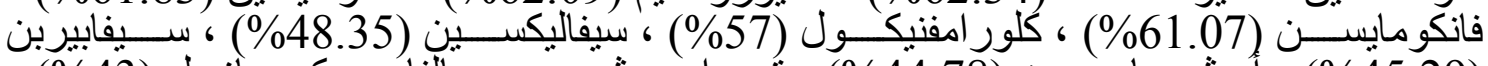

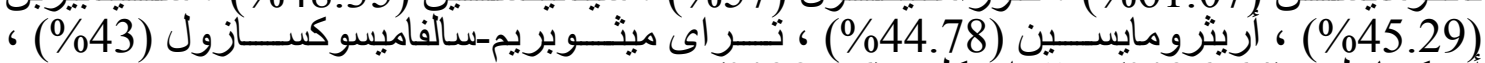

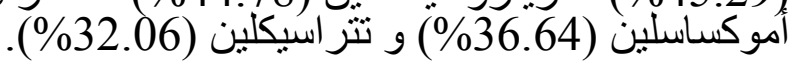

